Jiri Stodola $\square$

Petr Stodola

https://doi.org/10.21278/TOF.454022820

ISSN 1333-1124

eISSN 1849-1391

\title{
ANALYSIS AND MODEL OF CORROSION WEAR OF SELECTED MATERIALS USED IN SPECIAL VEHICLES
}

\begin{abstract}
Summary
The paper deals with the evaluation and modelling of corrosion wear of two standard materials used in the construction of special vehicles. The experimental research on corrosion wear involved the testing of two steels, EN 10131 and EN C22R, in a salt spray at 35 and $50{ }^{\circ} \mathrm{C}$ for $24,48,120$ and 144 hours. The model of the process of corrosion degradation of the tested materials uses the results of weight loss of the samples as a function of temperature and exposure time. The diagnostic macroscopic evaluation of corroded surfaces of the tested materials, using graphic (analogue) information of surfaces and its conversion into the digital form, is a completely new technology. The samples were photographed using a CCD camera, then pre-processed, segmented, and masks were created for the logic of deciding what corrosion is and what it is not. The final filtered image was created in binary values where logic 1 refers to a corroded and logic 0 to a non-corroded sample. The MATLAB software environment and the Image Processing Toolbox were used to process the results of the surface evaluation.
\end{abstract}

Key words: $\quad$ metal corrosion, salt spray corrosion tests, analysis, digital evaluation of material surfaces, evaluation and modelling of corrosion wear

\section{Introduction}

Although wear processes are inevitable during the life cycle of technical objects, they are also undesirable because they lead to massive degradation of materials, which often ends in a failure or even an accident. Specific requirements are placed on special vehicles over a relatively long and diverse life cycle. The vehicles are operated under extreme conditions (weather, terrain, time, operational conditions, maintenance, storage, different degree of load, etc.) for a relatively long time during which full use alternates with only partial or even no use. Corrosion is one of the most important mechanisms of wear. In fact, annual losses caused by corrosion have been estimated to be of about 5\% of GDP in developed countries. Corrosion is the spontaneous, gradual destruction of metals or non-metallic organic and inorganic materials (e.g. plastics) due to a chemical or electrochemical reaction with the environment. It can occur when gases, liquids, soils or various chemicals come into contact with the material. This disruption can manifest itself differently; from a change in appearance to complete degradation and disintegration of the whole. The main corrosion factors are atmospheric oxygen, hydroxide group $(\mathrm{OH})$ or anions formed from acids, e.g. $\mathrm{CO}_{3}{ }^{2-}, \mathrm{Cl}^{-}, \mathrm{NO}_{2}{ }^{-}, \mathrm{SO}_{4}{ }^{2-}$, etc. Hydrogen ions of acids are replaced by metal ions to form salts. 
The research into corrosion and corrosion wear is very complex, it has an interdisciplinary character and covers a wide area from basic research through special applications to the practical implementation of anti-corrosion measures for specific machines and equipment. The intensity of research corresponds to the results achieved at individual workplaces and these results are published. The authors draw attention to important contributions on the issue of material corrosion published from 2016 to 2020 [1 - 6].

Corrosion means the destruction of metals, but also non-metals, organic and even inorganic materials due to their chemical, electrochemical, or microbial and biological reactions with the ambient environment. Corrosion of ferrous metals can be classified according to the participation of oxygen in the ongoing process as aerobic (with oxygen) and anaerobic (without oxygen) [7 - 10]. Corrosion occurs in the atmosphere, gases, water and other liquids, soils and in various chemicals that are in contact with the corroding element.

The most used materials in special vehicles are metals or more precisely iron metals; therefore, they were used in the experiment described below [11]. The so-called corrosion process factors have a fundamental influence on the corrosion process. They are divided into external (ambient environment, pollution, temperature, humidity, pressure, exposure time, etc.) and internal factors (type and structure of material, chemical composition, production technology, processing, etc.).

The article deals with the selected results obtained from the experimental research focused on the evaluation and modelling of corrosion degradation processes of two selected materials used in special vehicles. The current development of information technology (IT) enables the practical application of IT in various areas, such as condition analysis and prediction of corrosion degradation of materials, etc. [12 - 13]. The aim of the research was to find, analyse, evaluate and process the course of corrosion wear with the help of IT, to evaluate the whole degradation process and to model the corrosion wear. Furthermore, the aim was to observe the increase in corrosion wear using the information obtained by digital recording of the sample surface and to determine the weight loss and the dependence of the corrosion rate on the exposure time. Finally, a model of the corrosion wear mechanism was created.

\section{Different types of corrosion}

Almost all materials that are in contact with the ambient environment are subject to corrosion degradation, namely by chemical, physical or biological mechanisms. Most metals and alloys are thermodynamically unstable and can spontaneously transition to the oxidized state. Table 1 shows the mathematical relations used in the paper, and Table 2 shows a summary of the used symbols. The thermodynamic stability of metals and alloys is determined by the change in Gibbs energy $\Delta G$, equation (1). Gibbs energy (thermodynamic change or chemical potential) represents the energy that 1 mole of a compound receives or transfers to the environment during its formation at constant values of temperature and pressure [14 - 16]. The magnitude of this energy allows spontaneous corrosion; the following applies: $\Delta G=0-$ the system is in equilibrium; $\Delta G>0-$ the process does not take place spontaneously; $\Delta G<0-$ the process takes place spontaneously. At the same time it applies that the system tries to go to equilibrium on its own and these transitions are accompanied by the formation of corrosion products, for example in the case of metals. Corrosion generally manifests itself in many ways, e.g. as uniform material loss, Fig. 1, selective or non-uniform material loss, formation of corrosion pits, crevices, spots, blisters, pitting, Fig. 2, pits, cracks, fissures, fractures, intercrystalline or transcrystalline corrosion, hydrogen, biological, vibrational, fatigue, erosion corrosion, etc. 


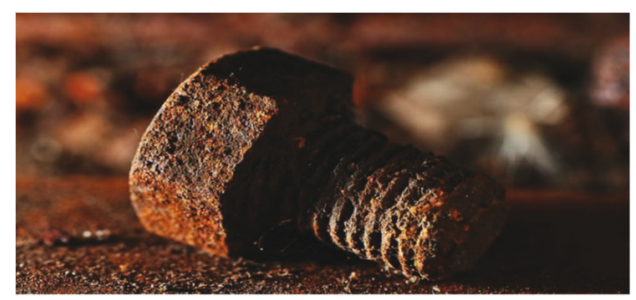

Fig. 1 Example of uniform corrosion

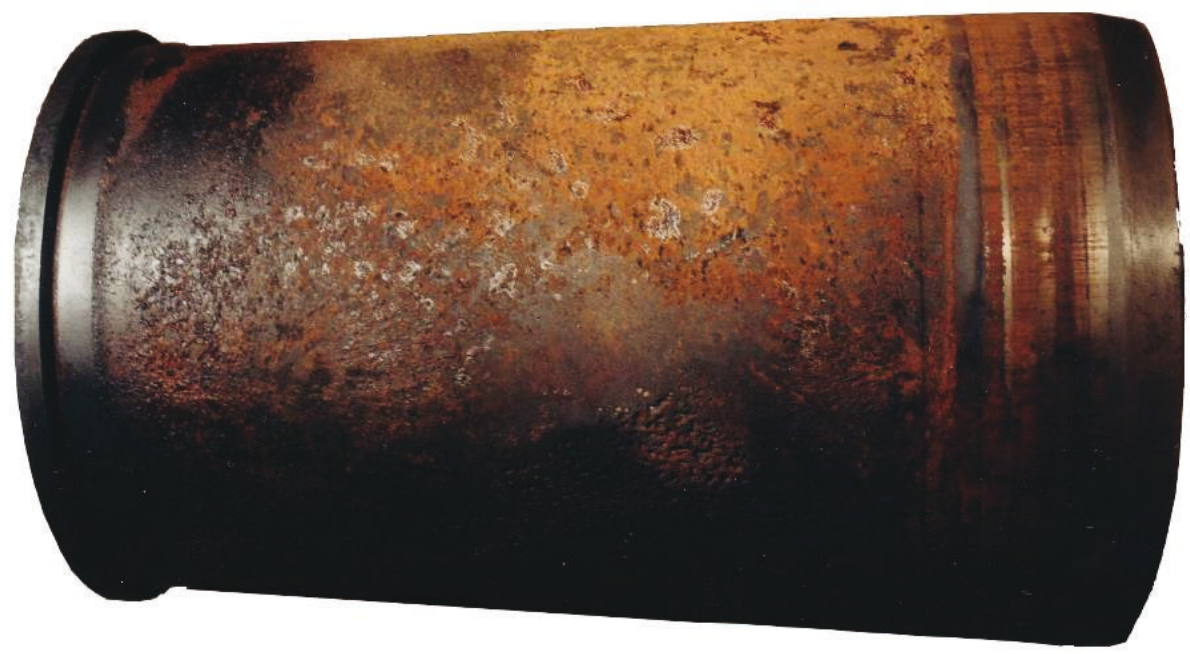

Fig. 2 Corrosion wear of combustion engine cylinder liner

Table 1 Summary of used equations

\begin{tabular}{|c|c|c|c|}
\hline $\begin{array}{c}\text { Equation } \\
\text { number }\end{array}$ & Equation & Unit & Description \\
\hline (1) & $\Delta G=\Delta H-T \cdot \Delta S$ & {$[\mathrm{~J}]$} & Gibbs energy \\
\hline (2) & $H=U+p \cdot V$ & {$[\mathrm{~J}]$} & Enthalpy change \\
\hline (3) & $S=-k \sum_{i} P_{i} \ln P_{i}$ & {$\left[\mathrm{~J} \cdot \mathrm{K}^{-1}\right]$,} & Entropy change \\
\hline (4) & $K=\frac{\Delta m}{S_{v_{z}}}$ & {$\left[\mathrm{~g} \cdot \mathrm{m}^{-2}\right]$} & Corrosion loss \\
\hline (5) & $U=\frac{K}{\rho}$ & {$[\mathrm{mm}]$} & Corrosion loss \\
\hline (6) & $v_{k}=\frac{K \cdot 365}{t}$ & $\begin{array}{c}{\left[\mathrm{g} \cdot \mathrm{m}^{-2} .\right.} \\
\left.\mathrm{yr}^{-1}\right]\end{array}$ & Corrosion rate \\
\hline (7) & $v_{k}=\frac{U \cdot 365}{t}$ & $\begin{array}{l}{[\mathrm{mm} \cdot} \\
\left.\mathrm{yr}^{-1}\right]\end{array}$ & Corrosion rate \\
\hline (8) & $V=\frac{U \cdot 365}{\rho}$ & {$\left[\mathrm{mm}^{3}\right]$} & $\begin{array}{l}\text { Volume of } \\
\text { material loss }\end{array}$ \\
\hline (9) & $v_{k}=\frac{\frac{V}{S_{v Z}}}{\tau} \cdot h_{r}$ & $\begin{array}{c}{\left[\mathrm{g} \cdot \mathrm{m}^{-2} \cdot\right.} \\
\left.\mathrm{yr}^{-1}\right] \\
{\left[\mathrm{mm}^{-}\right.} \\
\left.\mathrm{yr}^{-1}\right]\end{array}$ & Corrosion rate \\
\hline (10) & $y=b_{0} \cdot x+a_{0}$ & {$[-]$} & $\begin{array}{l}\text { Linear } \\
\text { regression }\end{array}$ \\
\hline
\end{tabular}




\begin{tabular}{|c|c|c|c|}
\hline $\begin{array}{c}\text { Equation } \\
\text { number }\end{array}$ & Equation & Unit & Description \\
\hline (11) & $\left(\begin{array}{cc}n & \sum x_{i} \\
\sum x_{i} & \sum x_{i}^{2}\end{array}\right) \cdot\left(\begin{array}{l}a_{0} \\
b_{0}\end{array}\right)=\left(\begin{array}{c}\sum y_{i} \\
\sum x_{i} y_{i}\end{array}\right)$ & {$[-]$} & $\begin{array}{l}\text { Linear } \\
\text { regression } \\
\text { matrix notation }\end{array}$ \\
\hline (12) & $y=c_{0} \cdot x^{2}+b_{0} \cdot x+a_{0}$ & {$[-]$} & $\begin{array}{l}\text { Quadratic } \\
\text { regression }\end{array}$ \\
\hline (13) & $\left(\begin{array}{ccc}n & \sum x_{i} & \sum x_{i}^{2} \\
\sum x_{i} & \sum x_{i}^{2} & \sum x_{i}^{3} \\
\Sigma x^{2} & \sum r^{3} & \sum x^{4}\end{array}\right) \cdot\left(\begin{array}{l}a_{0} \\
b_{0} \\
c_{0}\end{array}\right)==\left(\begin{array}{c}\sum y_{i} \\
\sum x_{i} y_{i} \\
\sum x^{2}\end{array}\right)$ & {$[-]$} & $\begin{array}{l}\text { Quadratic } \\
\text { regression } \\
\text { matrix notation }\end{array}$ \\
\hline (14) & $r_{x y}==\frac{\frac{1}{n} \sum_{i=1}^{n} x_{i} \cdot y_{i}-\bar{x} \cdot \overline{\bar{y}}}{\sqrt{\left(\frac{1}{n} \cdot \sum_{i=1}^{n} x_{i}^{2}-\bar{x}^{2}\right) \cdot\left(\frac{1}{n} \cdot \sum_{i=1}^{n} \cdot y_{i}^{2}-\bar{y}^{2}\right)}}$ & {$[-]$} & $\begin{array}{l}\text { Pearson } \\
\text { correlation } \\
\text { coefficient }\end{array}$ \\
\hline (15) & $r^{2}=\left(r_{x y}\right)^{2} \cdot 100$ & {$[-]$} & $\begin{array}{l}\text { Coefficient of } \\
\text { determination }\end{array}$ \\
\hline
\end{tabular}

Table 2 Summary of used symbols

\begin{tabular}{|c|l|}
\hline Symbol & \multicolumn{1}{|c|}{ Name and unit } \\
\hline$\Delta H$ & enthalpy change (energy stored in the system) $[\mathrm{J}]$ \\
\hline$T$ & thermodynamic temperature $[\mathrm{K}]$ \\
\hline$\Delta S$ & entropy change (uncertainties of the system) $\left[\mathrm{J} \cdot \mathrm{K}^{-1}\right]$ \\
\hline$p$ & pressure $[\mathrm{Pa}]$ \\
\hline$V$ & volume $\left[\mathrm{m}^{3}\right]$ \\
\hline$K, U$ & corrosion loss of surface weight $\left[\mathrm{g} \cdot \mathrm{m}^{-2}\right]$ or $[\mathrm{mm}]$ \\
\hline$\Delta m$ & weight difference before and after the test $[\mathrm{g}]$ \\
\hline$S_{v z}$ & area of the sample where corrosion takes $\mathrm{place}\left[\mathrm{m}^{2}\right]$ \\
\hline$\rho$ & material density $\left[\mathrm{kg} \cdot \mathrm{m}^{3}\right]$ \\
\hline$v_{k}$ & corrosion rate $\left[\mathrm{g} \cdot \mathrm{m}^{-2} \cdot \mathrm{yr}^{-1}\right]$ or $\left[\mathrm{mm} \cdot \mathrm{yr}^{-1}\right]$ \\
\hline$V$ & volume of material loss $\left[\mathrm{mm}^{3}\right]$ \\
\hline$t$ & exposure time of the test sample $[\mathrm{days}]$ \\
\hline$\tau$ & exposure time of the test sample $[\mathrm{h}]$ \\
\hline$h_{r}$ & number of hours per year $[8760$ to 8784$]$ \\
\hline
\end{tabular}

\subsection{Chemical corrosion}

Chemical corrosion takes place in non-conductive media (non-electrolytes, gases). It is caused by thermodynamic instability associated with the transition of the metal to a more stable state. The spontaneous process takes place if the difference between free enthalpies (energies) is negative and energy is released. Chemical corrosion also takes place in oxidizing or reducing environments. Metal oxidation is a process taking place at the phase interfaces of the metaloxide-oxygen system and in the emerging oxide layer. The whole process begins with the surface absorption of the oxidizing component, in which an ionic bond is formed between the oxygen and the surface metal atoms [17 - 18]. The metal gives two electrons to the oxygen atom, and the resulting bond is different from the bond of oxygen with the metal in the oxide. Oxygen absorption activity also depends on the spatial parameters of the material surface 
(edges, protrusions, radii, etc.). Absorption is affected by non-specific forces with low binding energy (Van der Vals), which is a reversible process, and by chemisorption, where chemically absorbed $\mathrm{O}_{2}$ particles are strongly bound on the surface by a bond similar to a chemical bond, which is an irreversible process. The nucleus and electrons are bound by attractive electric forces, while nucleons in the nucleus are bound by nuclear forces. For each system, we can talk about the so-called binding energy. This energy is equal to the work that must be done to decompose (e.g. corrode) the system into individual parts. The loss of the (rest) mass of an unstable system corresponding to the binding energy is called weight loss. Adsorption processes involve the accumulation of gases and dissolved absorbate on the surface of the adsorbent by the action of interfacial attractive forces. The result is the creation of a liquid or gaseous film on a solid surface. A distinction can be made between physical processes arising from Van der Waals attractive forces and processes that induce chemical bonds. Both of these mechanisms work in interaction with each other. The corrosion process ends with the formation of a layer of oxides, or other chemical reaction products. Chemical corrosion is influenced by various factors, the most important of which is temperature (heating regime, temperature changes and their fluctuations, temperature endurance, thermal shocks, etc.). It massively affects oxidation kinetics, oxidized layers properties, chemical reaction rate and diffusion rate. Another factor is the mechanical properties of the oxidation layers, in which tensile or compressive stress is created, which causes the destruction of these layers [19]. The kinetics of oxidation is also affected by the chemical composition of the gas. $\mathrm{SO}_{2}$ and other gaseous sulphur compounds, hydroxyl group $\mathrm{OH}, \mathrm{NO}_{2}$, water vapour, $\mathrm{CO}_{2}$, etc. are very aggressive.

\subsection{Electrochemical corrosion}

Electrochemical corrosion begins with the formation of local electrical cells and the thermodynamic instability of the metal in a given environment. The formation of electric cells is associated with different electrochemical potentials when two different metals interact with each other. The corroding metal loses its metallic character by an anodic reaction (oxidation process in which a positive charge of metal is transferred to the electrolyte) and becomes a cation (positively charged ion - atom or molecule) [11], [16] which dissolves in the solution, or becomes an insoluble compound. The anodic reaction (dissolution) is closely connected with the cathodic reaction by the exchange of an electric charge (negative charge of metal is transferred to the electrolyte), which is a reduction process. The rate of corrosion is then proportional to the magnitude of the current flow through the corrosion cell between the anode and the cathode. The anodic process is connected with the release of electrons, e.g. $F e \rightarrow F e^{2+}+2 e^{-}$. In order for this reaction to take place, the action at the cathode must be associated with the reduction of a depolarizer which absorbs the electrons released by the oxidation phenomenon. If the depolarization reaction did not occur, the anodic dissolution reaction could not take place either. During electrochemical corrosion on the metal surface, reductions in oxygen dissolved in water $\mathrm{O}_{2}+4 e+2 \mathrm{H}_{2} \mathrm{O} \rightarrow 4 \mathrm{OH}^{-}$or hydrogen cations, e.g. $2 \mathrm{H}^{+}+2 e^{-} \rightarrow \mathrm{H}_{2}$, take place. A potential difference (electromotive voltage of a galvanic cell) is created between the metal surface immersed in the electrolyte and mass particles, and charges are exchanged. Metal atoms are released from the metal bond and leave one or more electrons in the metal and pass into the solution in the form of cations. On the other hand, the electrolyte cations take up the required number of electrons on the metal surface, and are reduced and incorporated into the crystal lattice of the metal. Both of these phenomena are reversible. However, irreversible processes dominate in corrosion processes, which make it possible to assess the corrosion resistance of metals on the basis of electrochemical potentials. Higher potential means less susceptibility of metals to corrosion (precious metals) and vice versa. A thin layer of corrosion products on the surface changes the potential of the metal and provides it with some protection; a phenomenon called passivity occurs. Electrochemical corrosion is affected by internal and external factors. Internal 
factors include the location of the respective metal in the periodic table of elements, metal surface condition, load and stress, metal structure, etc. [19 - 20]. External factors include the potential of hydrogen $\mathrm{pH}$, salt concentration in the solution, corrosion inhibitor or stimulator content, temperature, pressure, ultrasound, radioactive radiation, etc.

Note:

Various components of the electrolyte can function as depolarizers, but in aqueous media they are most often hydrogen ions (hydrogen depolarization) or dissolved oxygen (oxygen depolarization). The value of the electrode potential is therefore crucial for the course of the electrode reaction, i.e. the corrosion of the given metal. There is a well-defined equilibrium potential for the equilibrium between the electrode and the solution. If the value of the potential of the electrode surface is equal to the equilibrium potential, then this reaction cannot take place externally as a reduction or oxidation. This is a state of dynamic equilibrium, where the rate of reduction and oxidation reactions are the same. The electrode reaction can only take place if the potential of the electrode surface is different from the equilibrium potential.

\section{Materials and methods}

Two construction materials were used to carry out the investigation into corrosion wear. The first tested material was EN 10131 non-alloy structural steel suitable for welding, used in the manufacture of parts for special vehicles and automobiles, which must withstand static and low dynamic stress. The second tested material was structural stainless steel EN C22R with the prescribed content of $\mathrm{C}, \mathrm{P}, \mathrm{S}, \mathrm{Si}$ and $\mathrm{Mn}$, which is used for the production of more stressed machine parts and internal combustion engine components. The samples had dimensions $100 \mathrm{x}$ $50 \times 2[\mathrm{~mm}]$ and an area of $0.005 \mathrm{~m}^{2}$. The chemical composition of both tested steels is given in Table 3. The presence of these elements was verified by the optical emission spectral analysis (CCD ICP spectrometer ACTIVA-M), and the results are shown in Table 3 [21].

Corrosion resistance of the two selected steels was verified by a standard test in a chamber (Liebisch S400MTR) with a salt spray. The test specimens were placed in a chamber where the temperature, the defined amount and size of saline solution droplets and the concentration of this solution were determined. After starting up the chamber, the saline solution starts acting on the test specimens at precise intervals and with the exact number of inputs. According to standard [10], [25] a corrosion test was performed in the corrosion chamber in a salt spray of a sodium chloride neutral solution of density $1,930 \mathrm{~kg} \cdot \mathrm{m}^{3}, \mathrm{pH}$ in the range $6.7-7.2$ and temperatures of $35^{\circ} \mathrm{C}$ and $50^{\circ} \mathrm{C}$. Ten specimens of EN C22R steel Vickers hardness $155 \mathrm{HV} 10$, size $100 \times 50 \mathrm{~mm}$ (area $0.005 \mathrm{~m}^{2}$ ), thickness $2 \mathrm{~mm}$, roughness $\mathrm{R}_{\mathrm{a}}=1,3 \mu \mathrm{m}$, and ten specimens of EN 10131 steel - Vickers hardness $138 \mathrm{HV} 10$ - were used for the test $21-22[14]$, [15].

Table 3 Chemical composition of tested steels in \%

\begin{tabular}{|c|c|c|c|c|c|c|c|c|}
\hline Steel grade & $\mathrm{C}$ & $\mathrm{Si}$ & $\mathrm{P}$ & $\mathrm{S}$ & $\mathrm{Mn}$ & $\mathrm{Cr}$ & $\mathrm{Mo}$ & $\mathrm{Ni}$ \\
\hline EN C22R & 0.226 & 0.379 & 0.020 & 0.040 & 0.450 & 0.210 & 0.057 & 0.102 \\
\hline EN 10131 & 0.200 & 0.007 & 0.017 & 0.016 & 0.686 & 0.005 & 0.009 & 0.003 \\
\hline
\end{tabular}

Note:

The choice of materials for testing was based on the tasks of the ASSISTANCE and VAROPS projects (DZRO FVT) related to very significant degradation of these materials during long-term storage. The partial goal was to obtain information on whether these materials are suitable for long-term storage or not or whether the massive degradation was caused by storage conditions or inappropriate corrosion protection.

Three basic criteria were chosen to evaluate the corrosion test, namely the percentage of corrosion on the sample surface (accuracy 5\%), weight loss and macroscopic evaluation of the sample surface. The percentage of corrosion was evaluated by digital recording of the sample surface and subsequent software evaluation, as briefly described below in the section on image 
processing [9]. The corrosion rate was calculated from the weight loss by accurate weighing before and after the test. We consider the weight loss to be the main parameter of corrosion degradation of the material. The time dependence of the corrosion rate was solved as a function of the increase in the ratio of the corroded sample surface to its weight and exposure time. We calculate the weight corrosion loss according to equations (4) and (5). The corrosion rate and material loss are determined from the weight losses according to equations (6) to (9). An example of corrosion losses and corrosion rate depending on exposure times and temperatures of 30 and $50{ }^{\circ} \mathrm{C}$ for the tested steel EN C22R is given in Table 4 [20] and for the tested steel EN 10131 in Table 5 [20]. An example of the sample surface after the corrosion test is shown in Fig. 3 [20 - 21], and that of the sample surface after cleaning is shown in Fig. 4 [23]. The average percentage of corrosion attack depending on the exposure time of steel EN C22R is given in Table 6 [20] and that of steel EN 10131 is given in Table 7 [22 - 23]. Examples of the dependence of weight losses $K$ on time and temperature are shown in Fig. 5 and the dependence of weight losses $U$ on time and temperature are shown in Fig. 6 [23]. An example of the dependence of the corrosion rate on time and temperature is shown in Fig. 7 [23].

Table 4 Corrosion rates and losses of tested steel EN C22R

\begin{tabular}{|l|c|c|c|c|}
\hline Exposure time $t[\mathrm{~h}]$ & 24 & 48 & 120 & 144 \\
\hline Corrosion loss $K\left[\mathrm{~g} \cdot \mathrm{m}^{-2}\right]$ & 113 & 184 & 380 & 481 \\
\hline Corrosion loss $U[\mathrm{~mm}]$ & 0,015 & 0,024 & 0.048 & 0.0623 \\
\hline Corrosion loss $[\%]$ & 2,40 & 3.90 & 8.14 & 10.40 \\
\hline Corrosion rate $v_{c}\left[\mathrm{~g} \cdot \mathrm{m}^{-2} \cdot \mathrm{yr}^{-1}\right]$ & 41245 & 33059 & 28043 & 29522 \\
\hline Corrosion rate $v_{c}\left[\mathrm{~mm} \cdot \mathrm{yr}^{-1}\right]$ & 5.26 & 4.31 & 3.53 & 3.81 \\
\hline Corrosion loss $K\left[\mathrm{~g} \cdot \mathrm{m}^{-2}\right]$ & 60.0 & 127 & 287 & 311 \\
\hline Corrosion loss $U[\mathrm{~mm}]$ & 0.008 & 0.016 & 0.036 & 0.040 \\
\hline Corrosion loss $[\%]$ & 2.49 & 3.95 & 8.22 & 10.45 \\
\hline Corrosion rate $v_{c}\left[\mathrm{~g} \cdot \mathrm{m}^{-2} \cdot \mathrm{yr}^{-1}\right]$ & 21900 & 23251 & 20951 & 18908 \\
\hline Corrosion rate $v_{c}\left[\mathrm{~mm} \cdot \mathrm{yr}^{-1}\right]$ & 2.79 & 2.97 & 2.67 & 2.41 \\
\hline
\end{tabular}

Table 5 Corrosion rates and losses of tested steel EN 10131

\begin{tabular}{|l|c|c|c|c|}
\hline Exposure time $t[\mathrm{~h}]$ & 24 & 48 & 120 & 144 \\
\hline Corrosion loss $K\left[\mathrm{~g} \cdot \mathrm{m}^{-2}\right]$ & 98.3 & 174 & 364 & 473 \\
\hline Corrosion loss $U[\mathrm{~mm}]$ & 0,01 & 0,03 & 0,05 & 0,06 \\
\hline Corrosion loss $[\%]$ & 0,65 & 1.16 & 2.43 & 3.15 \\
\hline Corrosion rate $v_{c}\left[\mathrm{~g} \cdot \mathrm{m}^{-2} \cdot \mathrm{yr}^{-1}\right]$ & 35846 & 31681 & 31612 & 28730 \\
\hline Corrosion rate $v_{c}\left[\mathrm{~mm} \cdot \mathrm{yr}^{-1}\right]$ & 4.57 & 4.03 & 3.40 & 3.70 \\
\hline Corrosion loss $K\left[\mathrm{~g} \cdot \mathrm{m}^{-2}\right]$ & 51.9 & 110 & 241 & 278 \\
\hline Corrosion loss $U[\mathrm{~mm}]$ & 0.001 & 0.01 & 0.03 & 0.036 \\
\hline Corrosion loss $[\%]$ & 0.34 & 0.77 & 1.61 & 1.86 \\
\hline Corrosion rate $v_{c}\left[\mathrm{~g} \cdot \mathrm{m}^{-2} \cdot \mathrm{yr}^{-1}\right]$ & 18907 & 20077 & 17564 & 16936 \\
\hline Corrosion rate $v_{c}\left[\mathrm{~mm} \cdot \mathrm{yr}^{-1}\right]$ & 2.41 & 2.97 & 2.61 & 2.41 \\
\hline
\end{tabular}

Note:

In Tables 3 and 4, lines 2 to 6 apply to the temperature of $50^{\circ} \mathrm{C}$ and lines 7 to 11 to the temperature of $35^{\circ} \mathrm{C}$. 
Table 6 Surface corrosion of EN C22R at temperatures of 35 and $50{ }^{\circ} \mathrm{C}$ expressed as percentage

\begin{tabular}{|c|c|c|c|c|c|}
\hline No. & Time [min] & \% of corros. at $35^{\circ} \mathrm{C}$ & No. & Time [min] & \% of corros. at $50^{\circ} \mathrm{C}$ \\
\hline$\underline{1}$ & 0 & 1.09 & 1 & 0 & 1.18 \\
\hline$\underline{2}$ & 30 & 6.07 & 2 & 30 & 30.57 \\
\hline$\underline{3}$ & 60 & 16.43 & 3 & 60 & 45.14 \\
\hline$\underline{4}$ & 90 & 27.10 & 4 & 90 & 54.97 \\
\hline$\underline{5}$ & 120 & 33.07 & 5 & 120 & 66.31 \\
\hline$\underline{6}$ & 150 & 42.88 & 6 & 150 & 69.80 \\
\hline$\underline{7}$ & 180 & 51.71 & 7 & 180 & 79.85 \\
\hline$\underline{8}$ & 210 & 62.58 & 8 & 210 & 80.44 \\
\hline$\underline{9}$ & 240 & 68.85 & 9 & 240 & 85.55 \\
\hline$\underline{10}$ & 270 & 70.90 & 10 & 270 & 89.33 \\
\hline$\underline{11}$ & 300 & 74.75 & 11 & 300 & 89.81 \\
\hline$\underline{12}$ & 330 & 77.17 & 12 & 330 & 91.81 \\
\hline
\end{tabular}

Table 7 Surface corrosion of EN 10131 at temperatures of 35 and $50{ }^{\circ} \mathrm{C}$ expressed as percentage

\begin{tabular}{|c|c|c|c|c|c|}
\hline No. & Time [min] & \% of corros. at $35^{\circ} \mathrm{C}$ & No. & Time $[\mathrm{min}]$ & \% of corros. at $50^{\circ} \mathrm{C}$ \\
\hline$\underline{1}$ & 0 & 0.74 & 1 & 0 & 1.68 \\
\hline$\underline{2}$ & 30 & 5.26 & 2 & 30 & 46.65 \\
\hline$\underline{3}$ & 60 & 35.96 & 3 & 60 & 64.78 \\
\hline$\underline{4}$ & 90 & 52.89 & 4 & 90 & 80.62 \\
\hline$\underline{5}$ & 120 & 60.53 & 5 & 120 & 82.96 \\
\hline$\underline{6}$ & 150 & 65.33 & 6 & 150 & 95.14 \\
\hline$\underline{8}$ & 180 & 71.69 & 7 & 180 & 87.85 \\
\hline$\underline{9}$ & 210 & 76.12 & 8 & 210 & 87.85 \\
\hline$\underline{10}$ & 240 & 77.45 & 9 & 240 & 90.64 \\
\hline$\underline{11}$ & 270 & 79.48 & 10 & 270 & 92.94 \\
\hline$\underline{12}$ & 330 & 81.60 & 11 & 300 & 93.57 \\
\hline
\end{tabular}

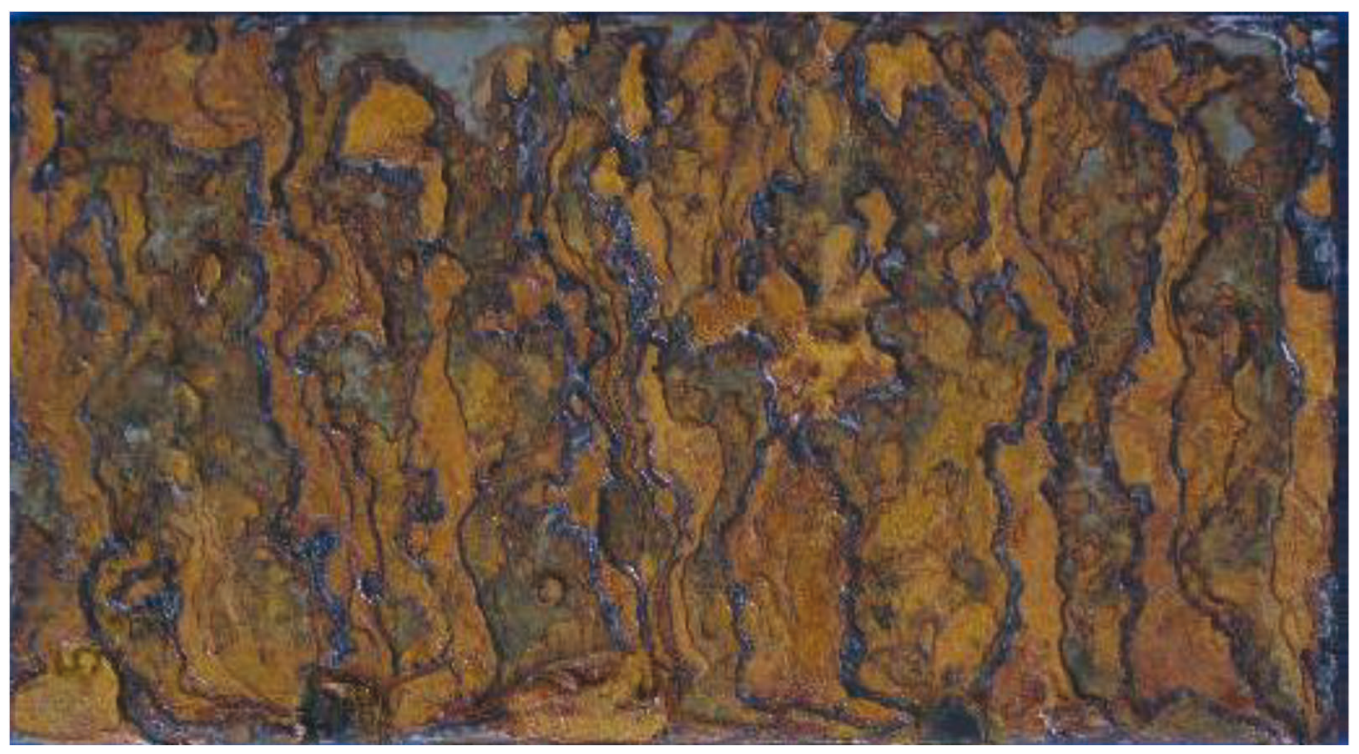

Fig. 3 Example of sample surface after corrosion test 


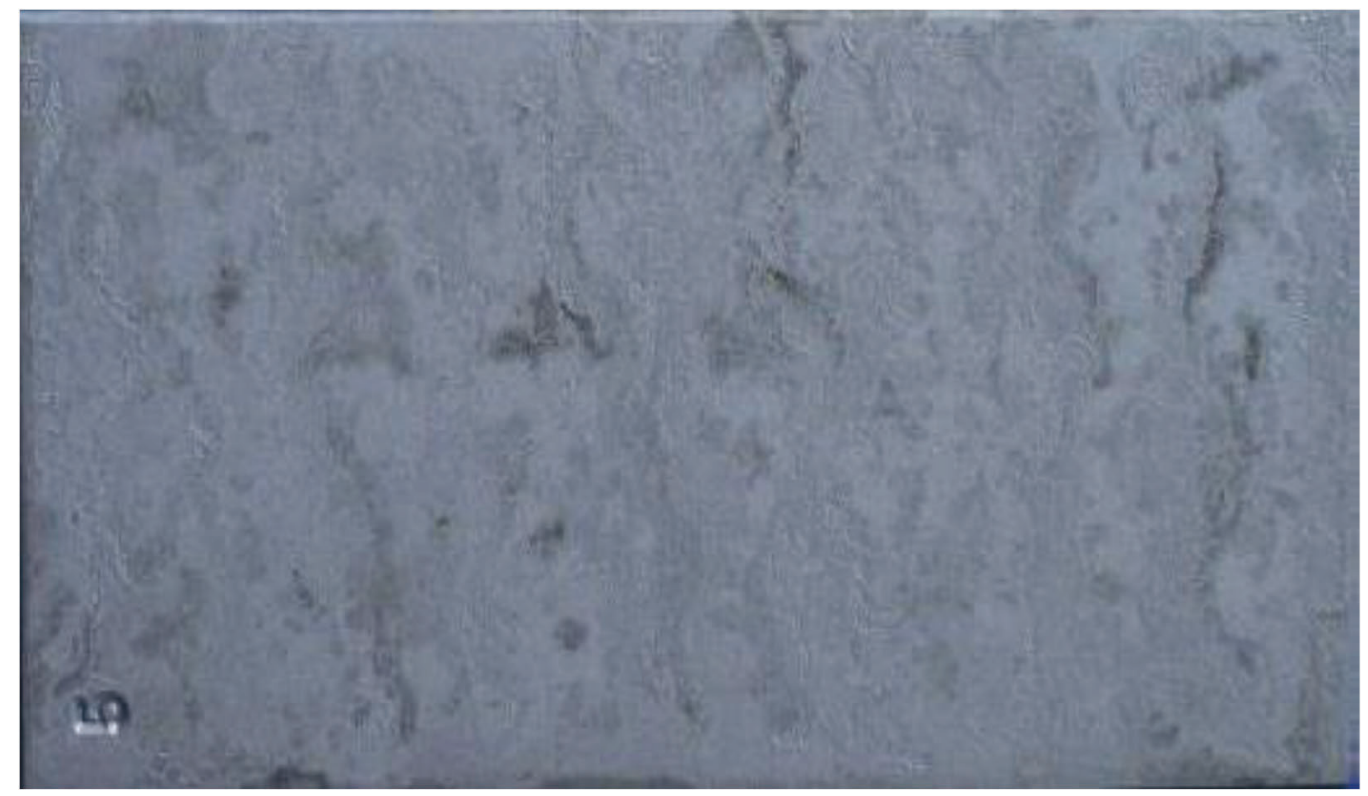

Fig. 4 Example of sample surface after corrosion test and cleaning [14], [21]

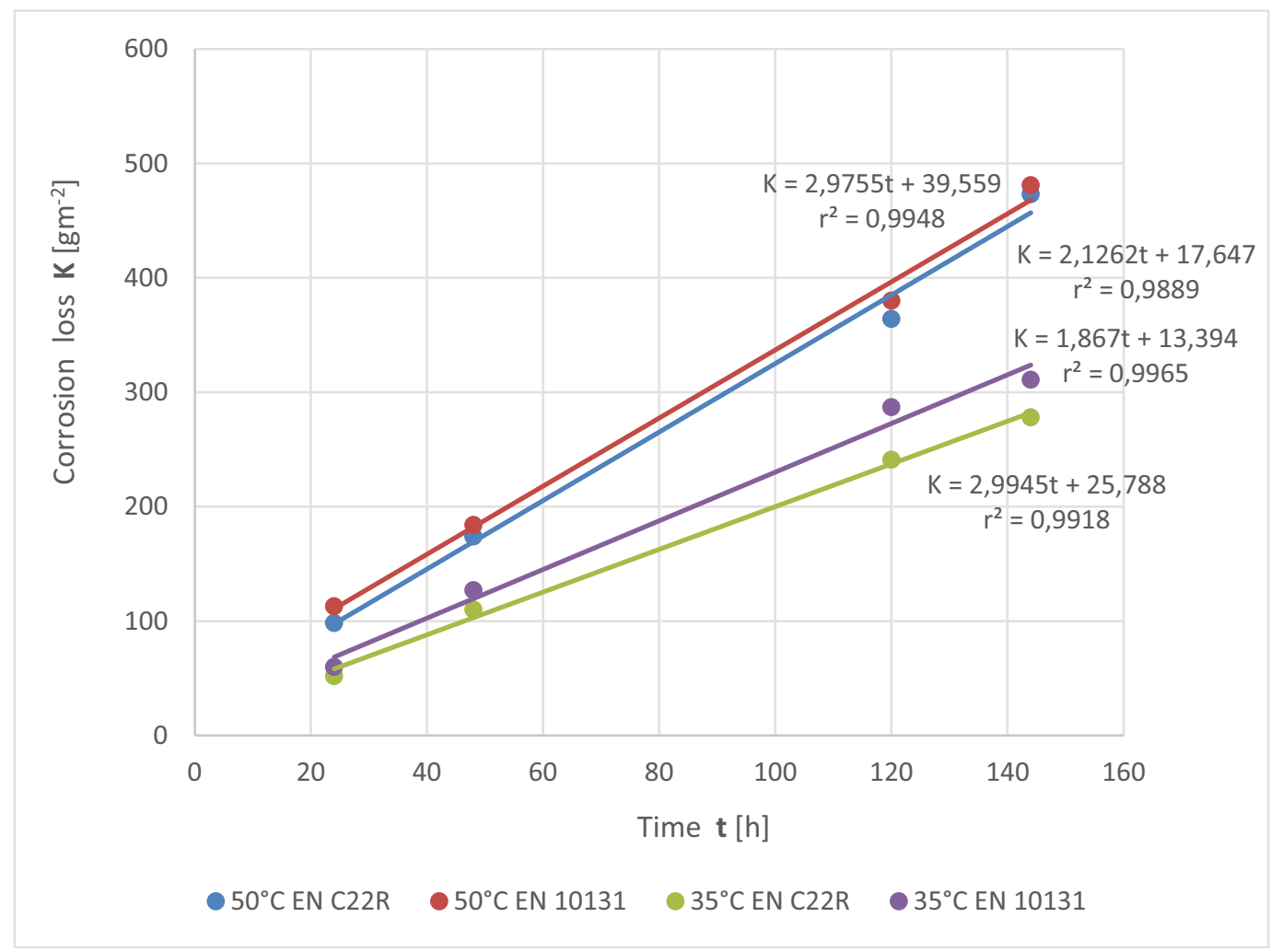

Fig. 5 Example of dependence of corrosion loss $\mathbf{K}$ on time $\mathbf{t}$ and temperature 14], [21] 


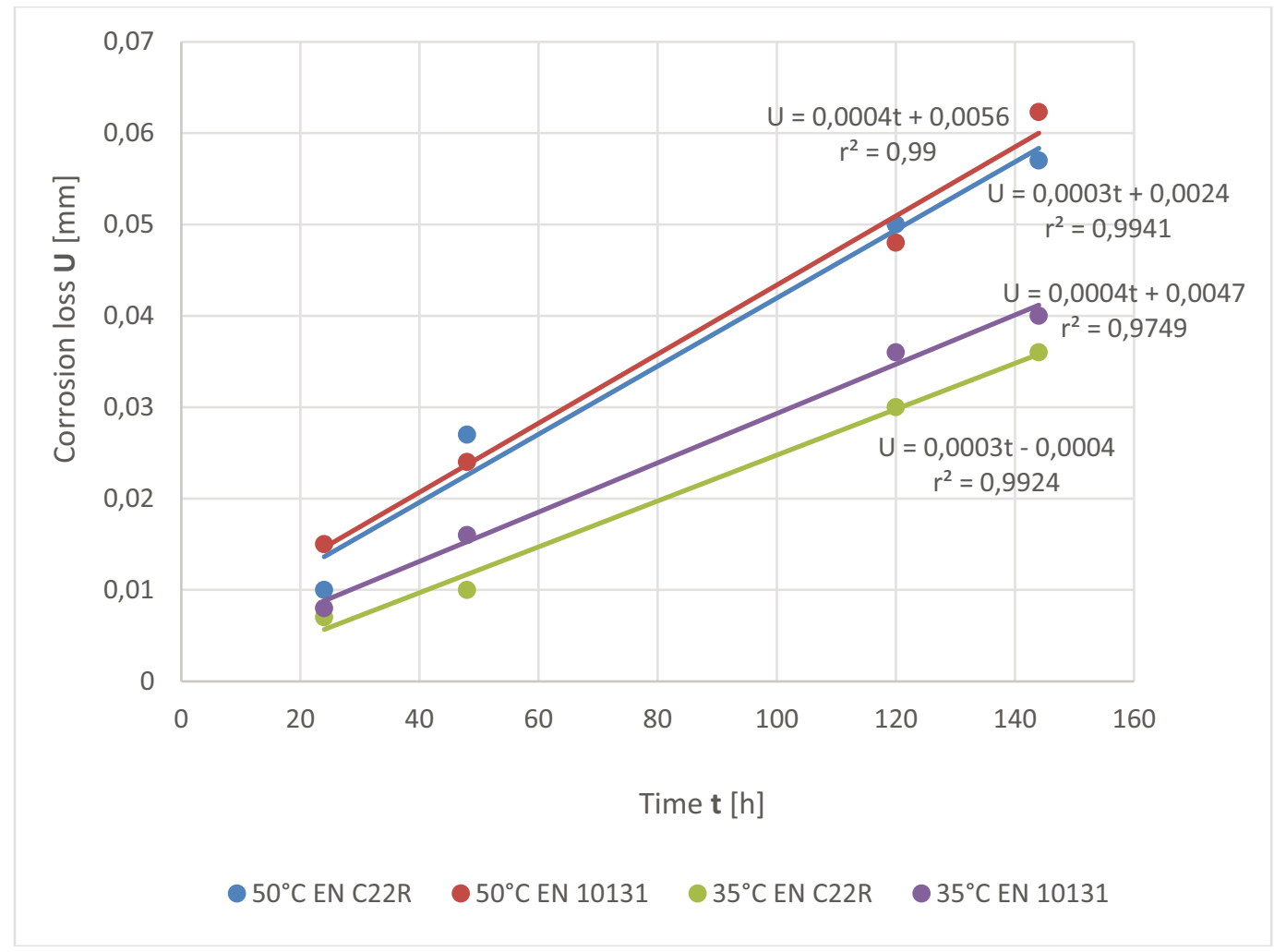

Fig. 6 Example of dependence of corrosion loss $\mathbf{U}$ on time $t$ and temperature [14], [21]

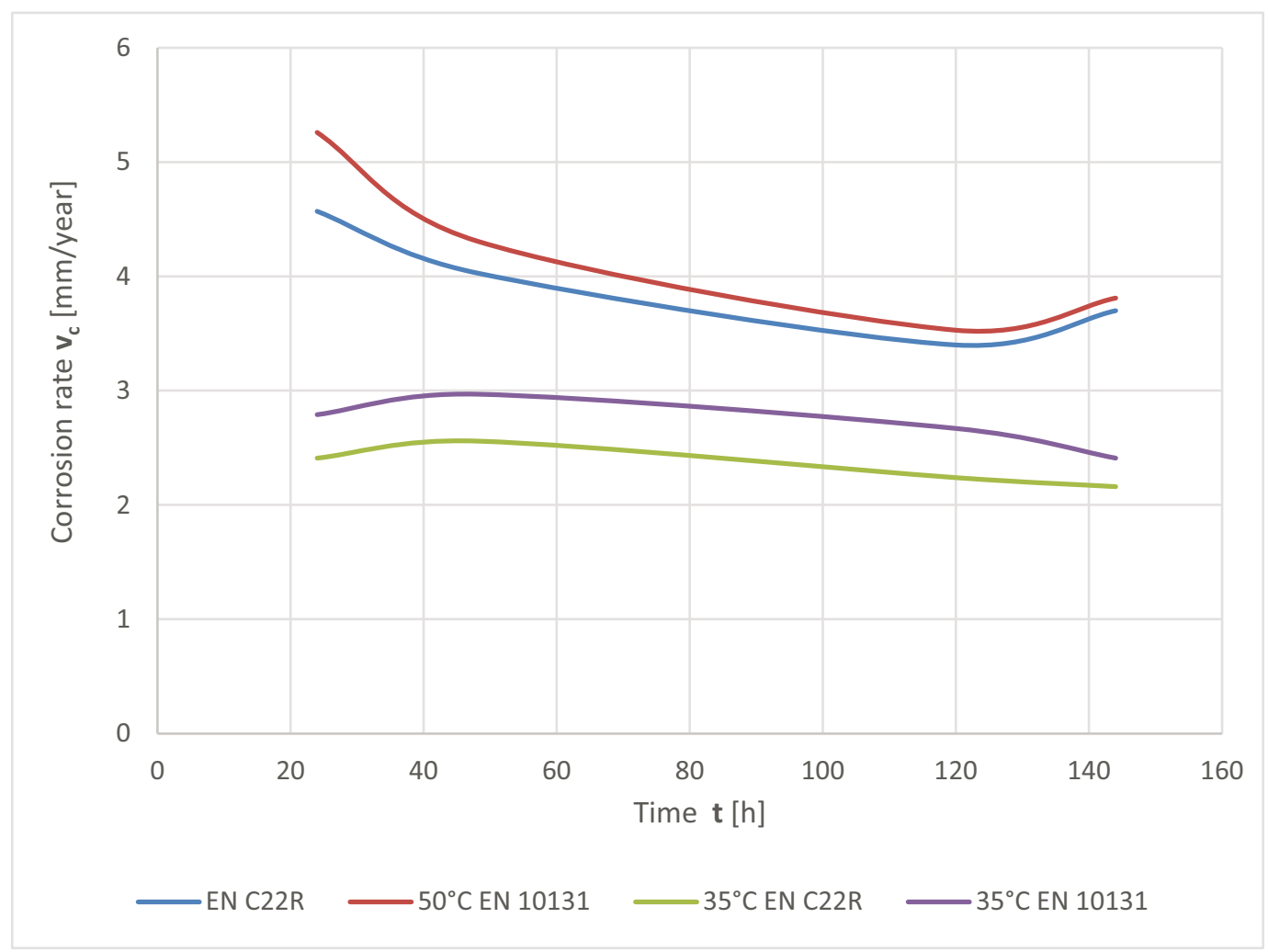

Fig. 7 Example of dependence of corrosion rate on time and temperature [14], [21] 


\section{Image processing}

In order to capture the course of the increase in corrosion wear of the samples of the selected metallic materials, the samples were continuously photographed during the experiment with a frequency of one image every 30 minutes. Furthermore, the conversion of graphic (analogue) information from photographs into a digital form was performed [14], [20]. Subsequently, the digital image of the photos was processed with the Image Processing Toolbox in the MATLAB environment. The image was stored in a two-dimensional matrix, where each value of the matrix represented a certain point of the image (pixel). In the primary colour image, this point of the image consists of three numbers forming the RGB colour model (red, green, blue). One hundred per cent of the value is white light, and $0 \%$ of the value is black. All known colours were expressed by a certain combination of RGB numbers, where each component is in the range $0-255$, so the camcorder or the camera recorded approximately 16,8 million colours, or exactly $256^{3}$. In order to recognize the required objects (corrosion features) in the image, it was necessary to find a characteristic attribute that allows to distinguish this object from the background. Furthermore, the individual points of the image were examined to decide whether they do or do not belong to the required object (in our case, the manifestation of surface corrosion). This operation is called image segmentation and the result is a so-called indexed image. Each point of the image (pixel) belonging to an object is assigned a positive value and all other points are zero. The exact classification of the objects was affected by the relative ambiguity of the images, noise and insignificant objects on the surface of the samples. In practice, there is no universal procedure for image segmentation, so the goal was to simulate a complex task, namely, the recognizing function of the human eye and brain. Furthermore, brightness corrections of images (histogram, increase and decrease in brightness, gamma correction, equalization - adjustment of contrast of the histogram) and spatial transformations of the image including resizing, focusing, etc. were performed. Such image processing is beyond the scope of this text. The segmentation based on the principle of edges (Sobel filter) was tested, which is suitable for automatic evaluation of surfaces (blistering, paint defects, porosity, etc.). In general, the evaluation of corrosion attack included four operations, namely a standard microscope image, filter segmentation, highlighting important information, and calculating areas using logical operators. An example of evaluating the surface porosity of a test sample is shown in Fig. 8.

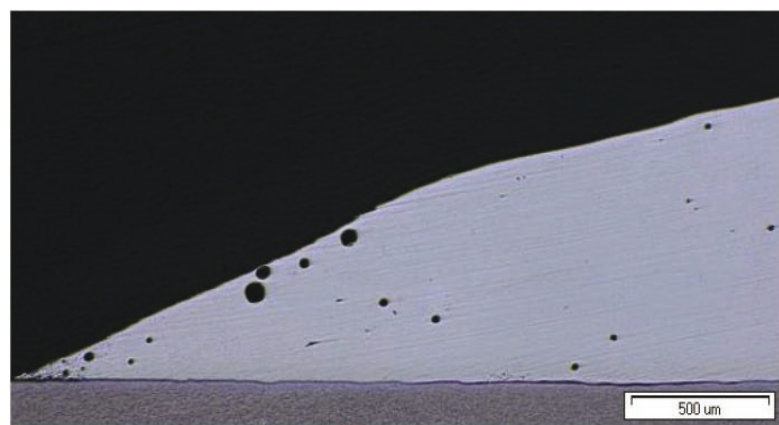

a)

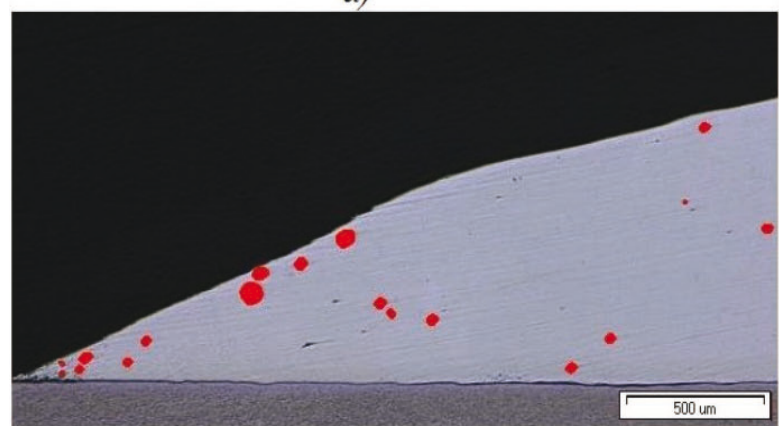

c)

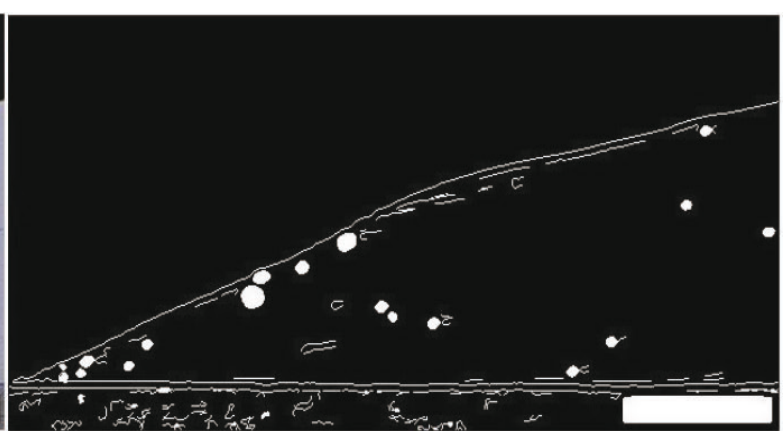

b)

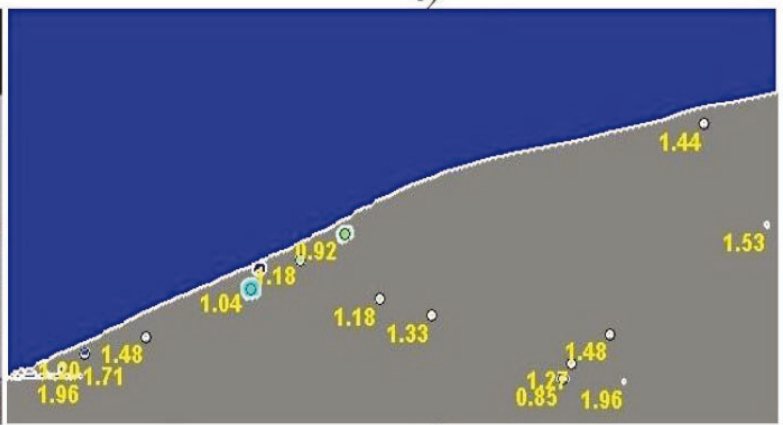

d)

Fig. 8 Evaluation of surface porosity of tested sample: a) microscope image; b) Sobel filter segmentation; c) highlighting important information; d) calculated areas using logical operations 
Adaptive thresholding (the first derivative of the Gaussian function) was a usable method of segmentation. The images of corrosion of the samples surface were in the form of dots, which were enlarged and joined into larger areas, while their colour also changed. To create the selection logic, i.e. to recognize what is corrosion and what is not, a so-called comparison mask was created, from which the values of the image points (pixels) were selected. Furthermore, spectra of steel samples with corrosion and steel samples without corrosion were created, and histograms of RGB components were generated for this image information (Fig. 9). The boundaries of the comparison mask were determined from the sample spectrum and a filter was created using logical operators and conditions, which allowed the filtering of individual components according to the selected mask and the final image was created only in binary units, where logical 1 refers to corroded steel and logical 0 to corrosion-free steel [11], [20]. After segmentation, the percentage of surface corrosion was calculated.

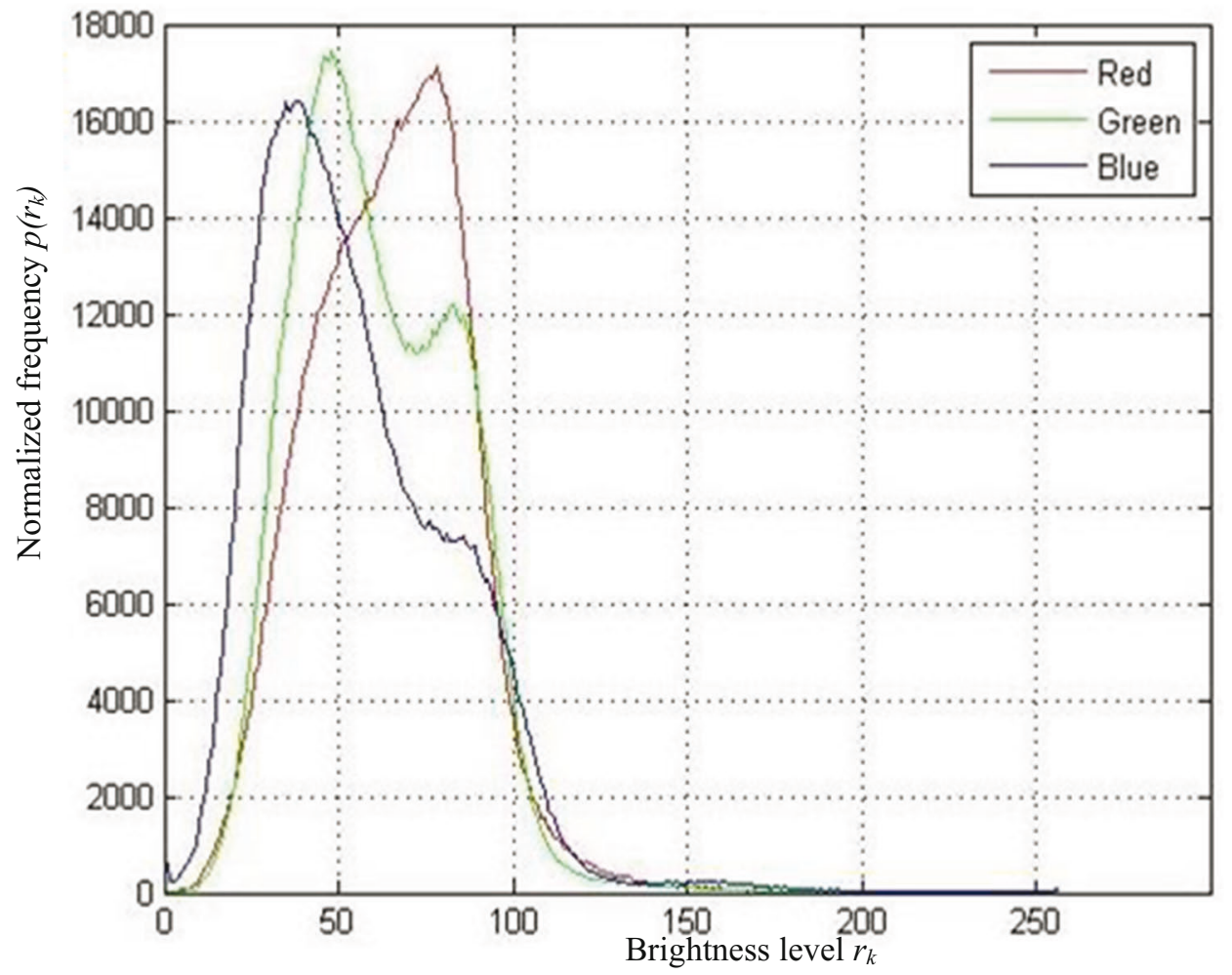

Fig. 9 Histogram of steel masks with corrosion of RGB colour model

Note:

The histogram of the digital image with L levels $\langle 0, L-1\rangle$ is a discrete function $h\left(r_{k}\right)=n_{k}$, where $r_{k}$ is the $k$ th brightness level and $n_{k}$ is the number of points of the image with brightness $r_{k}$, and $p\left(r_{k}\right)$ is the probability density of the brightness level occurrence $r_{k}$.

\section{Discussion}

After the corrosion test, the surface of the test specimens was evaluated visually and then digitally. Already after about 30 minutes of exposing the sample in the chamber, local areas of corrosion attack of uneven pitting began to appear. With an increased exposure, surface and deep corrosion increased. The surface was generally covered with corrosion after 120 hours at a temperature of $50{ }^{\circ} \mathrm{C}$ and after 144 hours at a temperature of $35^{\circ} \mathrm{C}$; during the test, the colour, roughness and penetration of corrosion into the sample material changed. EN C22R, which contains higher amounts of chromium, molybdenum and nickel, showed increased corrosion resistance. 
For the purpose of the analysis of the corroded area of the samples, the samples were removed from the corrosion chamber every 30 minutes, and the surface image was digitally recorded and processed according to the described methodology. The recording of the corrosion attack in percentage was performed by 240 and 288 measurements of the sample and the subsequent averaging of the values. Linear regression of equations (10) and (11) was used to evaluate the weight loss of the materials. The statistical dependence between the corrosion loss and the exposure time was determined by Pearson's correlation coefficient $r_{x y}$, equation (14), which had, for example, for steel ENC22R the value of 0.989 , which represents a strong dependence, and it also allowed to interpolate the regression line. Next, the coefficient of determination $r^{2}$, equation (15), was calculated, which represented the proportionality of common variance, which can be interpreted as information by how much \% a change in one variable affects the other variable. The value of the coefficient of determination was $99.59 \%$. The statistical estimate of the linear regression equation was in the form of $y=1.867 x+$ 13.394. In this linear regression equation, $a_{0}=13.394$ is a constant expressing the expected level of the dependent variable at zero value of the independent variable, and the regression coefficient $b_{0}=1.867$ refers to the number of units of measure the dependent variable changes when the independent variable changes by one unit of measure [23]. Regression coefficient $b_{0}>0$, and thus it is a direct dependence. Furthermore, quadratic regression analysis was used for the dependence of corrosion percentage of the sample on the exposure time, equations (12), (13). It was necessary to determine three coefficients for the quadratic analysis. Cramer's rule was used as a solution, individual determinants of the third degree were calculated using Strauss's rule. Variable $x$ represented the exposure time, $y$ the percentage of the corroded surface area, and $n$ the number of measurements. The statistical estimate of the quadratic regression equation was in the form $y=-3.5355 \cdot 10^{-7} x^{2}+0.011+13.199772$. Graphically, the trends of the dependence of the sample surface corrosion in $\%$ on the exposure time were interpolated linearly, or by second order polynomial. Regression functions and correlation coefficients for both steels were also calculated. Using the algorithm in the MATLAB program and the regression and correlation analysis, mathematical models of regression dependencies were built, which allow predicting the extent of surface corrosion or weight loss of the material [24]. The given data give more information about the corrosion degradation of a specific material under given conditions (temperature, environment).

\section{Conclusion}

In the paper, the authors present one selected method of testing the corrosion resistance of two materials used in special vehicles. Current advanced technologies enable the use of modern diagnostic tools for obtaining information to evaluate the actual technical condition of a technical object during its use. Using technical knowledge and IT, it is possible to process a large amount of data and thus more precisely define individual types of dependencies without relatively laborious manual calculations. The authors believe that the main benefit of the IT used will be the creation of databases (big data) containing the results of corrosion tests for individual engineering materials. The results of testing the dependence of temperatures, corrosion rates and losses can be used, for example, to predict the future state. With the implementation of each new measurement, the databases expand and other measurements are more accurate. The relationships defined in this way can be compared with databases and used to predict the future state. When implementing each new measurement, the information libraries are expanded and subsequent measurements are more accurate. The corrosion process is affected by a relatively large number of internal and external factors, so it is necessary to experimentally test the used materials and the conditions in which they operate. The paper evaluates the corrosion test in a salt spray, where the variables were bath temperature and exposure time. The standard corrosion test was improved when new IT options were used as they significantly expand the possibilities of diagnostics and enable prediction of the future 
condition. Thanks to these modern methods it is possible to define various dependencies relatively precisely and to create databases of metallic materials that can be used for making predictions. In this particular case, it is necessary to state that the results obtained in this investigation are not universally valid for all types of corrosion attack and other types of steel, and that the tested materials showed uniform chemical corrosion. The investigation confirmed that the corrosion loss of the material increases with an increase in temperature. In general, it can be stated that the article presents partial new findings in the field of:

- the description of corrosion with respect to the speed of the process and factors that influence corrosion attack using digital technologies,

- the design of an image analysis procedure for corrosion detection and evaluation of the percentage of corrosion on sample surfaces,

- the development of a user software for calculations of weight losses and corrosion rates according to international standards [7 - 8], [10] and [25].

The results show that it is necessary to perform further tests with different materials and other variables, so that particular materials, exposure times and the specific corrosive environment are fully described, the results verified and then commonly used in practice. The article presents proven methodological procedures universally applicable to other tests and materials.

\section{Acknowledgments}

The presented investigation has been carried out with the support of the ASISSTANCE and VAROPS projects (DZRO FVT), University of Defence Brno, Czech Republic.

\section{REFERENCES}

[1] Fayyad, Eman M., Kishor Kumar Sadasivuni, Deepalekshmi Ponnamma, Mariam Al Ali Al-Maadeed. (2016). Oleic acid-grafted chitosan/graphene oxide composite coating for corrosion protection of carbon steel. Carbohydrate polymers 51. pp 871-878. https://doi.org/10.1016/j.carbpol.2016.06.001

[2] Bandil, Kapil, Himanshu Vashisth, Sourav Kumar, Lokesh Verma, Anbesh Jamwal, Devendra Kumar, Neera Singh, Kishor Kumar Sadasivuni, and Pallav Gupta. (2019). Microstructural, mechanical and corrosion behaviour of Al-Si alloy reinforced with SiC metal matrix composite. Journal of Composite Materials 53, No. 28-30. pp 4215-4223. https://doi.org/10.1177/0021998319856679

[3] Jamwal, Anbesh, Prem Prakash, Devendra Kumar, Neera Singh, Kishor K. Sadasivuni, Kumar Harshit, Sumit Gupta, and Pallav Gupta. (2019). Microstructure, wear and corrosion characteristics of Cu matrix reinforced SiC-graphite hybrid composites. Journal of Composite Materials 53, No. 18. pp 2545-2553. https://doi.org/10.1177/0021998319832961

[4] Jlassi, Khouloud, A. Bahgat Radwan, Kishor Kumar Sadasivuni, Miroslav Mrlik, Aboubakr M. Abdullah, Mohamed M. Chehimi, and Igor Krupa. (2018). Anti-corrosive and oil sensitive coatings based on epoxy/polyaniline/magnetite-clay composites through diazonium interfacial chemistry. Scientific reports 8, No. 1. pp 1-13. https://doi.org/10.1038/s41598-018-31508-0

[5] Patel, Dhruvi, Krutarth Makwana, Manjusha B. Shirdhonkar, and Ketan C. Kuperkar. (2020). Electrochemical response and computational approach on surface-active ionic liquid (SAIL) in metal corrosion inhibition. Emergent Materials 3. pp 161-168. https://doi.org/10.1007/s42247-020-00099-w

[6] Fayyad, Eman M., Aboubakr M. Abdullah, Mohammad K. Hassan, Adel M. Mohamed, George Jarjoura, and Zoheir Farhat. (2018). Recent advances in electroless-plated Ni-P and its composites for erosion and corrosion applications: a review. Emergent Materials 1, No. 1 pp 3-24. https://doi.org/10.1007/s42247-018-0010-4

[7] G15-02 Standard Terminology Relating to Corrosion and Corrosion Testing. (2002). ASTM Book of Standards. Vol. 03.02. Wear and Erosion: Metal Corrosion.

[8] ASM Handbook: (2003). Corrosion Fundamentals, Testing, and Protection. Vol. 13, ASM International. ISBN: 0-87170-705-5.

[9] Cramer S, D., Covino, B, S. Jr. (2003). Introduction to Corrosion Testing and Evaluation; Corrosion: Fundamentals, Testing, and Protection. ASM Handbook, Vol. 13A. ASM International, p. 419. https://doi.org/10.31399/asm.hb.v13a.a0003638 
[10] CSN EN ISO 8044. Corrosion of metals and alloys - basic terms and definitions. Available at: https://www.iso.org/obp/ui\#iso:std:8044:ed-4:v1:en (in Czech).

[11] Robles, D. (2012). Potable Water Pipe Condition Assessment for a High Rise Condominium in the Pacific Northwest. GSG Group, Inc. Dan Robles, PE.

[12] Majstas, D, Macova, P., Kreislova, K., Prihoda, J. (2017). Iron alloys outdoor corrosion and laboratory simulation - comparison. In METAL 2017 Conference Proceedings. 1st Edition 2018. Ostrava: TANGER Ltd. ISBN 978-80-87294-79-6. pp 912-917.

[13] Stodola, J., Peslova, F., Krmela, J. (2008). Worn out machine parts. Monography, University of Defence Brno. ISBN 978-80-7231-552-9 (in Czech) p. 197.

[14] Oravec, I. (2014). Corrosion Wear Modelling of Typical Materials Occurring on Special Techniques. Doctoral dissertation. Alexander Dubcek University of Trencin. (in Slovak). p. 101.

[15] Breakell, M Siegwart, K Foster, D Marshall, M Hodgson, R Cottis, S Lyon (2005). Management of Accelerated Low Water Corrosion in Steel Maritime Structures, Vol. 634 of CIRIA Series, ISBN 086017-634-7

[16] Zuo, R., Örnek, D., Syrett, B, C., Green, R., Hsu, C, H., Mansfeld, F. B., Wood, T, K. (2004). Inhibiting mild steel corrosion from sulfate-reducing bacteria using antimicrobial-producing biofilms in ThreeMile-Island process water. Appl. Microbiol. Biotech. 64. pp 275-283. https://doi.org/10.1007/s00253-003-1403-7

[17] Schweitzer, P, A. (2010) Fundamentals of corrosion-Mechanisms, Causes and Preventative Methods. Taylor and Francis Group, LLC ISBN 978-1-4200-6770-5, p. 25.

[18] Gerhardus H., Koch, M., Brongers, P, H., Thompson, N, G., Y.Virmani, P.M., Payer, J, H. (2001). Corrosion Costs and Preventive Strategies in the U.S.A. - report by CC Technologies Laboratories, Inc. to Federal Highway Administration (FHWA).

[19] NACE Corrosion Costs Study (2014). Cor-Pro.com. NACE. 2013-11-12.

[20] Leach, R. (2011). Optical measurement of surface topography. Springer. ISBN 978-3-642-12011-4. p. 338. https://doi.org/10.1007/978-3-642-12012-1

[21] Stodola, J., Breznicka, A. (2019). Corrosion wear of selected materials of special vehicles. Internal research report. Alexander Dubcek University of Trencin, (in Slovak). p 110.

[22] Stodola, J, Breznicka, A. (2019). Degradation of Technique and Material in Long-Term Storage. In: Armament and Technics of Armed Forces 2019. Academy of the Armed Forces of General M. R. Stefanik Liptovsky Mikulas and Ministry of Defence of the Slovak Republic. ISBN 978-80-8040-585-4. (in Czech). pp 255-264.

[23] Stodola, J., Krobot, Z., Breznicka, A., Jelinek, J., Stodola, P. (2020). Degradation of Equipment and Material in Long-Term Storage. In: V. Ostaševičius. Transport Means 2020. Lithuania: Kaunas University of Technology. Vol. 24. ISSN 1822-296X. pp 716-720.

[24] Stodola, J., Jelinek, J., Breznicka, A., Krobot, Z., Stodola, P. (2020). Corrosive Wear of Materials Used in Special Mobile Equipment. In: V. Ostaševičius. Transport Means 2020. Lithuania: Kaunas University of Technology, 2020, Vol. 24. ISSN 1822-296X. pp 676-682.

[25] ČSN ISO 9227 (038132) (2007) Corrosion tests in artificial atmospheres - salt spray tests. Czech Standards Institute Prague. (in Czech). P. 24.

Submitted: $\quad$ 08.9.2020

Accepted: $\quad$ 13.9.2021
Prof. Dr.Sc. Jiri Stodola*

University of Defence Brno, Faculty of

Military Technology, Brno,

Czech Republic

Prof. Ph.D. Petr Stodola

University of Defence Brno, Faculty of

Military Leadership, Brno,

Czech Republic

petr.stodola@unob.cz

*Corresponding author:

jiri.stodola@unob.cz 